\title{
O trabalho na contemporaneidade: estudo sobre as dimensões que trabalhadores de uma organização pública associam ao trabalho
}

\author{
Work on contemporaneity: an study about the \\ dimensions that a public organization workers \\ associate to work
}

\author{
Ana Cristina Batista-dos-Santos ${ }^{1}$ \\ Monique Fonseca Cardoso ${ }^{2}$ \\ Dinara Leslye ${ }^{3}$ \\ Anderson Luiz Rezende Mól ${ }^{4}$ \\ José Arimatés de Oliveira ${ }^{5}$
}

\section{Resumo}

O texto se situa entre aqueles que tomam o trabalho como uma dimensão epistemológica e praxiológica fundamental, entendendo seu estudo como necessário, em tempos de mudanças, no devir histórico. Propõe-se a identificar as dimensões que os trabalhadores de uma organização pública associam ao trabalho na contemporaneidade e socializa os resultados de uma pesquisa em que foi utilizado um questionário estruturado como instrumento de coleta de dados. $O$ tratamento dos dados coletados ocorreu através da técnica análise fatorial. O modelo final foi constituído de quatro fatores, denominados: dimensões do trabalho flexível, dimensões do trabalho tradicional, dimensões indesejadas do trabalho e dimensões vitais e morais do trabalho. Os fatores indicam um hibridismo nas relações que os

Doutora em Administração pela Universidade Federal do Rio Grande do Norte - UFRN. Professora e pesquisadora da Universidade Estadual do Ceará - UECE.

2 Mestre em Administração pela Universidade Federal do Rio Grande do Norte - UFRN. Professora e pequisadora da Universidade Estadual da Paraíba - UEPB.

3 Mestre em Administração pela Universidade Federal do Rio Grande do Norte - UFRN. Professora da Unversidade Federal do Rio Grande do Norte.

4 Doutor em Administração pela Universidade Federal de Lavras - UFLA. Professor da Universidade Federal do Rio Grande do Norte.

5 Pós-Doutor em Psicologia Organizacional pela Universitat de Barcelona. Professor da Universidade Federal do Rio Grande do Norte. 
respondentes estabelecem entre as variáveis e o trabalho, ora tendendo a ressaltar relações com as dimensões flexíveis, ora apontando uma relação com variáveis que remontam ao trabalho sob o capitalismo tradicional, ora em ambas, numa espécie de amalgamento. Os resultados permitiram refletir sobre as mudanças nas concepções de trabalho de servidores em face da visão gerencialista que tem sido propagada nas últimas décadas e possibilitou a reflexão no que diz respeito ao quanto se conserva da tradição no que hoje se chama de flexível.

Palavras-chave: Trabalho. Flexibilidade. Capitalismo. Contemporaneidade.

\section{Abstract}

This article considers work as a fundamental epistemological and praxiological dimension. Its goal is identify the dimensions that a group of workers associate with work at contemporaneity. It socializes results of a exploratory and descriptive research, on which it was used a questioner conceived from the theoretical references. The sample was composed of one hundred and forty six public workers. It was apply factorial analysis, and oblique rotation. The model was formed by six factors: dimensions of flexible work, dimensions of satisfactory and compensator work, undesired dimensions on work, dimensions of traditional work, dimensions of control at the traditional work, dimensions of control at the flexible work. The factors indicate a hybridism at relations between variables and work. They tend emphasize sometimes flexible, other times traditional dimensions, and both, simultaneously. The results leads a reflection about changes of conceptions of work from public workers face to the new public management's vision, and about how much from the traditional is preserved on what it nowadays called flexible.

Keywords: Work. Flexibility. Capitalism. Contemporaneity.

\section{Introdução}

O trabalho constitui tema de cunho multidisciplinar, interesse que é de áreas diversas como sociologia, psicologia, educação, engenharia de produção e administração. Nesta última, em geral numa interface com o campo da psicologia, o trabalho é estudado tanto no contexto internacional quanto no brasileiro, sob várias perspectivas e nomenclaturas, predominando pesquisas sobre: (i) sentidos do trabalho (ANTUNES, 2003a); (ii) significado e sentidos do trabalho (MORIN; TONELLI; PLIOPAS, 2007, TOLFO; PICCININI 2007); (iii) concepções 
do trabalho (BORGES, 1999); psicodinâmica do trabalho (Mendes, 2007a), e (iv) trabalho e carreiras (BENDASSOLLI, 2009).

Entretanto, a intensidade de estudos sobre o trabalho não traz a marca da consensualidade, quer conceitual, político-ideológica, nem mesmo epistemológica, além de ter como pano de fundo histórico um debate acerca da sua centralidade nos dias atuais. Há, como Offe (1989), os que questionam a centralidade da categoria trabalho, argumentando que o mesmo não é mais tratado, diferentemente da modernidade, como o mais importante princípio de organização das estruturas sociais, donde o modelo de pesquisa social centrado no mesmo estaria em declínio. Porém, cumpre observar que "enquanto se opera no plano gnosiológico a desconstrução [discursiva] do trabalho, paralelamente, no mundo real, no plano ontológico, este se converte (novamente?) em uma das mais explosivas questões da contemporaneidade" (ANTUNES, 2005, p. 39), dadas as substantivas mudanças que se operam, cotidianamente, na vida dos que "têm" trabalho e daqueles que se acham socialmente privados deste.

Este texto se situa entre aqueles que entendem o trabalho como categoria epistemológica e praxiológica fundamental. Concorda com Albornoz (2008) ao afirmar que o trabalho integra a história da humanidade ao longo do tempo, nas mais variadas formas de suas emergências, mas, principalmente pelo trabalho modificar o próprio homem, mediando a constituição da sua identidade e a construção permanente da sociedade. Este estudo entende o trabalho como instância que media as relações entre o homem e a natureza, o homem consigo mesmo e com seus semelhantes, e o homem com a cultura. É, portanto, categoria cuja centralidade se dá tanto nas esferas social, política e econômica (ANTUNES, 2003a; 2003b; 2005), quanto ao nível individual e existencial, onde a subjetividade e suas demandas se destacam (CODO; SORATTO; VASQUES-MENEZES, 2004, MENDES, 2007a). Partindo, portanto, do pressuposto de que o trabalho é uma categoria estruturante, ao mesmo tempo, das dimensões particulares (o indivíduo em sua subjetividade) e coletivas (a sociedade em suas 
múltiplas dimensões), entende-se aqui que o mesmo deve ser objeto especial de estudo em tempos de mudanças, no devir histórico.

A contemporaneidade tem sido descrita como tempo de intensas e rápidas mudanças, de processos de rupturas, descontinuidades e incertezas, configurando, numa perspectiva sociológica, o que Bauman (2001) chama de modernidade líquida ou fluida, que, desde o ponto de vista econômico, é narrada como tempos de capitalismo flexível (BOLTANSKI; CHIAPELLO, 2009, HARVEY, 2008, SENNETT, 2006, 2007). Entende-se aqui que as formas como os trabalhadores concebem e conceituam o trabalho e se (re)posicionam em suas relações de trabalho guardam relação com as mudanças em curso.

Este trabalho argumenta que tais mudanças são assimiladas e reproduzidas de maneira intensa no contexto das relações privadas de produção, porém, percebe-se igualmente a emergência de novas concepções das relações de trabalho e da gestão no contexto das organizações públicas. Atualmente, são crescentes as produções acadêmicas com a denominação Nova Gestão Pública ou Reforma Gerencial (BRESSER-PEREIRA, 2010), que trazem para a pauta da administração pública conteúdos frequentemente associados apenas à administração empresarial (MADUREIRA; RODRIGUES, 2006, OSÓRIO, 2005), sob uma noção gerencialista. Na visão de Bresser-Pereira (2010), a reforma gerencial desencadeada na Grã-Bretanha nos anos 80 e no Brasil a partir de 1995, foi o caminho adotado para contraposição às ideias neoliberais de minimização do Estado, constituindo-se num elemento central do processo de transição do Estado Democrático Liberal para o Estado Democrático Social.

Porém, Estado Social e Reforma Gerencial constituem uma relação dialética (BRESSER-PEREIRA, 2010), uma vez que o Estado Social demanda um aumento por vezes considerável da organização estatal tendo em vista oferecer serviços de consumo coletivo, sendo a Reforma Gerencial utilizada para legitimar esse tipo de Estado pelos caminhos da racionalização administrativa para uma prestação de serviços eficiente. Assim é que a lógica própria à gestão privada, conceitualmente coerente 
com ideais neoliberais, é utilizada como caminho para contraposição e consolidação de um Estado não liberal, o Estado Social, face às investidas neoliberais. Certamente, isso redunda em mudanças no contexto do mundo do trabalho no âmbito das organizações públicas.

Contra esse pano de fundo, este texto entende que estudar a categoria trabalho face às recentes mudanças, inclui, necessariamente, conhecer o que os trabalhadores pensam a respeito do mesmo, identificando que conteúdos eles associam ao trabalho na contemporaneidade. $\mathrm{O}$ artigo tem, então, o seguinte objetivo: identificar as dimensões que um grupo de trabalhadores associa ao trabalho na contemporaneidade.

O texto contém quatro partes além desta introdução. A parte dois revisa a literatura sobre trabalho: conceitos, história e sua relação com o capitalismo. A terceira parte detalha a estratégia metodológica utilizada durante a pesquisa de campo, seguida da quarta parte, que apresenta e discute os resultados. As considerações finais são apresentadas ao final do artigo.

\section{Trabalho: conceitos e história}

O trabalho é um daqueles "conceitos básicos em torno dos quais as narrativas ortodoxas da condição humana tendem a se desenvolver" (BAUMAN, 2001, p. 15). Ele figura entre os conceitos com múltiplos significados (ALBORNOZ, 2008) e controvérsias, apresentando-se polissêmico e multifacetado. Dois termos são associados historicamente ao trabalho: labor e trabalho, embora frequentemente a distinção existente entre eles seja ignorada nas teorias modernas (ARENDT, 1995).

Quanto ao labor, Arendt (1995) esclarece que o seu sentido está relacionado ao processo de suprimento das necessidades vitais e de reprodução da vida humana, daí sua inscrição ao nível do corpo, instância em que reside o processo natural da vida. Na Antiguidade, o labor estava restrito à esfera privada. Na Grécia Antiga, a figura do escravo tipificava o exercício do labor. 
Ressalte-se, contudo, que o escravo grego da Antiguidade não guarda relação com o sentido de escravatura assumido na modernidade, isto é, com vistas a gerar lucro para o senhor de escravos. O que estava posto ao escravo era o atendimento das necessidades da vida, sua e do seu senhor, através do corpo, representando a ação corporal com vistas à sobrevivência. Nesse sentido, o trabalho era visto de maneira negativa, como atividade reservada aos inferiores daquela sociedade, com forte teor degradante e desgastante. Na sociedade grega, o ócio era a antítese do labor, sendo valorizado e restrito aos homens livres. O labor associa-se ao conceito de animal laborans, aquele que é compelido servilmente pelas necessidades do corpo, não deixando resultado permanente através da sua atividade (ARENDT, 1995).

Correspondente ao termo "trabalho" estaria o homo faber, entendido como o que usa suas mãos e corpo de maneira livre, tomandoos instrumentos que produzem objetos de uso caracterizados, dentre outras coisas, por sua durabilidade. O artesão das guildas medievais tipifica o conceito de homo faber em sentido puro, uma vez que era livre e desenvolvia sua autonomia em pelo menos quatro aspectos: (i) quanto à concepção do trabalho; (ii) quanto ao processo de realização do trabalho; (iii) em relação ao destino do trabalho (uso ou venda); (iv) em relação ao seu corpo e ao seu tempo no trabalho (AKTOUF, 2004).

Para Arendt (1995), labor e trabalho se encontram na modernidade, sob o sistema capitalista de produção, face à produtividade inerente ao conceito de labor, produtividade que reside na força humana capaz de gerar excedentes para além das necessidades de reprodução de um único corpo. A autora entende, então, que é "mediante violenta opressão numa sociedade de escravos, ou mediante a exploração na sociedade capitalista que a produtividade pode ser canalizada de tal forma que o labor de alguns é bastante para a vida de todos" (ARENDT, 1995, p. 76). É próprio da modernidade tornar o trabalho uma atividade institucionalizada, com importância decisiva para a vida do homem em sociedade (RAMOS, 2009). 


\subsection{O trabalho no capitalismo tradicional}

A conceituação moderna de trabalho constitui-se a partir dos sistemas de racionalização, e pode-se afirmar que tais sistemas são consequências de mudanças ocorridas no ambiente sociocultural, de uma transformação da ação do homem em relação à natureza e à sociedade, decorrentes da Revolução Industrial. Mediante a utilização extensiva das máquinas, o homem passa a mudar de atitude diante da natureza. $\mathrm{Na}$ sociedade capitalista, o sentido anterior do trabalho como forma de realização produtiva e reprodutiva no e pelo trabalho é transformado, perdendo o sentido de criação de coisas úteis para a realização humana, tornando-se meio para acumulação de capital. Essa nova significação de trabalho exalta seu valor e Iho atribui alta centralidade, tornando-o instrumento para o sucesso econômico, embora, num mesmo movimento, seja fonte de estranhamento, já que o processo e o produto final do trabalho passam a ser controlados pelo empregador, que detém os meios de produção e exerce sobre o trabalhador sua capacidade de dominação (ALBORNOZ, 2008; BENDASSOLLI, 2009; BORGES, 1999; RAMOS, 2009).

Essa nova ética do trabalho converte o conceito religioso de vocação, ligando-o à profissão e conectando-o à identidade moral do homem. Assim, o trabalho assume uma posição de categoria-chave na definição do humano, na modernidade, adquirindo a posição de atividade realizada na esfera pública, reconhecida como útil, e através da qual se recebe uma remuneração (BENDASSOLLI, 2009, GORZ, 2003). É nesse contexto que emerge a concepção moderna de trabalho, baseada no vocabulário econômico e na divisão e racionalização dos processos. O exercício do trabalho fica submetido a premissas mais convergentes com as exigências produtivas do sistema de produção ascendente, tais como a racionalização e as diretrizes científicas. Dessa forma, constituiuse o ambiente propício ao desenvolvimento de disciplinas científicas aplicadas à organização do trabalho. Nesse cenário, ascendem os estudos como os de tempos e movimentos de Taylor, e o sistema fordista de produção (ANTUNES, 2005; BENDASSOLLI, 2009; RAMOS, 2009). 
Os Princípios da Administração Científica de Taylor (1986), apesar de não serem pioneiros no estudo de técnicas e da racionalização do trabalho, adequaram-se mais plenamente às exigências da fase monopolista do capitalismo. O taylorismo preconizava a decomposição do processo de trabalho em movimentos elementares e a redução do tempo de execução das operações ao mínimo, padronizando-os. Procuravase, então, encontrar a melhor maneira de desempenhar determinada tarefa. Dessa forma, a aplicação do método científico legitimava a separação entre o saber e o fazer, de forma que o conhecimento do trabalhador transferia-se a um sistema impessoal no qual o controle sobre seu trabalho não ficava mais a cargo de si. Essa cisão entre gerência, concepção, controle e execução já estava bem avançada quando Henry Ford introduziu seu dia de oito horas e cinco dólares em sua linha de montagem. No que tange ao processo de trabalho, o fordismo focava-se em diminuir o desperdício de tempo e de espaço, e acreditava que a recompensa do trabalhador deveria ser correspondente à sua produtividade. $O$ recebimento da remuneração privilegiada estava condicionado à submissão dos trabalhadores à manutenção de altas taxas de produtividade, independente das condições de trabalho (FARIA, 2008; HARVEY, 2008; RAMOS, 2009).

O binômio taylorismo-fordismo baseava-se no parcelamento, intensificação do volume e ritmo, repetição, especialização, e padronização do trabalho. Essas características, aliadas ao contexto político-econômico, à racionalidade científica e à materialidade do sistema, revestiam-no de rigidez. A alienação dos trabalhadores do produto de seu trabalho, a rotina entediante, e a intensificação do ritmo e volume do trabalho tornam-se causa de adoecimento e sofrimento. Assim, o sistema precisava adaptar-se para fazer frente à resistência dos trabalhadores aos efeitos de passividade e apatia causados pela repetição. Atualmente, busca-se a solução de tais malefícios por meio da eliminação da rotina, de forma que o arcabouço de mecanismos utilizados para resolução desses problemas pode ser resumido a uma única palavra (de ordem): a flexibilidade (HARVEY, 2008; SENNETT, 2007). 


\subsection{O trabalho no capitalismo flexível}

$\mathrm{Na}$ atualidade, há uma "normalização da mudança pela perpetuação de tudo como volátil e transitório" (VIEIRA; CALDAS, 2006, P. 6). Importantes transformações podem ser percebidas nas diversas esferas da vida humana associada, dentre as quais se destacam: as revoluções tecnológicas, a mundialização do capital, a elevação da competitividade entre os agentes econômicos com proeminência de uma sociedade do consumo, além de variadas maneiras inovadoras de relações organizacionais (CHESNAIS, 1996; CLEGG; HARDY, 1998; FONTENELLE, 2008, GURGEL, 2003, MENDES, 2007b, SENNETT, 2007, 2006, VIEIRA; CALDAS, 2006). O mundo do trabalho vem sendo tomado pela perspectiva da flexibilidade, a qual se propaga em pelo menos três níveis: produtivo, organizacional e administrativo. Uma nova lógica geradora de modelos inovadores é estabelecida fundamentada no tripé produção flexível, organizações flexíveis e administração flexível (FONTENELLE, 2008, GURGEL, 2003, MENDES, 2007b, SENNETT, 2007), configurando um novo "espírito" do capitalismo, o flexível, potencializado a partir dos anos 1990 (BOLTANSKI ; CHIAPELLO, 2009).

As transformações pelas quais passam as organizações internamente são narradas como consequências das turbulências e instabilidades do ambiente externo. Ganham força os enfoques ambientais fortemente calcados na lógica da competitividade. Acirrada concorrência mercadológica, acelerado desenvolvimento tecnológico, e clientes conscientes e com altos níveis de exigência são narrados como forças ambientais demandantes de uma gestão flexível nas organizações, pautada nas pressões por adaptabilidade e mudança constantes, estas também exigidas do trabalhador. O objetivo é a eliminação do modelo empresarial anterior, integrado verticalmente no que diz respeito à produção, e visivelmente hierarquizado no que se refere ao design organizacional, hierarquia baseada na autoridade definida e favorável ao desenvolvimento de carreiras vitalícias em uma mesma organização (BOLTANSKI; CHIAPELLO, 2009). Em seu lugar, surge a lógica das equipes ou times de trabalho. O capitalismo flexível se fundamenta na permanente reinvenção das instituições, se 
apresentando, pelo menos discursivamente, como antítese da rígida lógica burocrática de organização (SENNETT, 2007). Com uma nova representação de empresa, ataca-se a burocracia sob o argumento de que ela empobrece o trabalho e aliena o indivíduo; utiliza-se de um ideário de libertação pelas vias da participação, num sistema em que mais autonomia significa mais implicação (GAULEJAC, 2007).

Nos novos modelos organizacionais, que implantam a flexibilidade e adaptação através de processos de reengenharia, espera-se que os trabalhadores estejam abertos à mudança e aprendizagem contínuas, sejam versáteis e assumam individualmente a responsabilidade e riscos advindos das mudanças na trajetória profissional (BRAGA; LIMA, 2007; PINTO ; LEMOS, 2006), portando-se como trabalhadores flexíveis (FONTENELLE, 2008), que assumem a concorrência entre si não como resultante de um modelo de gestão de pessoas pautado nos mesmos modelos estratégicos de competitividade mercadológica, mas "como se este fosse o funcionamento normal, ligado à natureza das coisas. [Assim], a empresa espera de seus empregados que sejam fortes, dinâmicos, competentes, disponíveis, seguros de si, capazes de enfrentar as contradições e de preencher objetivos sempre mais ambiciosos." (GAULEJAC, 2007, p. 216).

Consequentemente, é gerada no cotidiano organizacional uma inédita cultura de ansiedade (FONTENELLE, 2008), derivada de uma cultura da conquista, na qual os trabalhadores estão frequentemente cercados pelo risco de desenvolverem patologias ligadas ao trabalho, como a depressão, o burnout, o estresse, a hiperatividade, dentre outras (GAULEJAC, 2007).

As mudanças (des)contínuas no mundo do trabalho demandam profissionais cada vez melhor preparados e fala-se de um novo trabalhador, mais participativo, polivalente e mais escolarizado (MATTOSO, 1995), com capacidade para desenvolver novas habilidades e descobrir capacidades potenciais, de acordo com as mudanças na realidade externa (FONTENELLE, 2008). Contudo, as qualificações necessárias em uma economia flexível são de um novo tipo, baseadas em aptidões "portáteis", como saber ouvir, trabalhar em equipe, ser criativo, 
participativo e estar aberto a novas experiências além de pronto para assumir riscos. Certamente, essa nova perspectiva traz implicações no tocante às concepções de trabalho e às relações que se estabelecem, no cotidiano, na vida do sujeito que trabalha.

\subsection{Do teórico ao empírico}

De acordo com a literatura revisada, há um bloco de variáveis que podem ser atreladas diretamente ao trabalho no capitalismo tradicional, bem como outras que guardam maior relação com o trabalho sob o capitalismo flexível. Há, ainda, aquelas que, de acordo com a literatura, emergem nos dois contextos, embora com peculiaridades de cada época, figurando como espécies de variáveis híbridas. O Quadro 1 sintetiza essa revisão teórica, apresentando as variáveis privilegiadas neste trabalho a partir dos principais autores consultados. Essas variáveis foram utilizadas para composição do instrumento de pesquisa, conforme será apresentado na estratégia metodológica, a seguir.

Quadro 1 - Variáveis teóricas para composição do instrumento de pesquisa

\begin{tabular}{|c|c|}
\hline 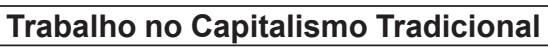 & Da \\
\hline $\begin{array}{l}\text { Padronização, Frustração, Facilidade, } \\
\text { Segurança, Sofrimento, Repetição, } \\
\text { Proteção, Vocação, Hierarquia, } \\
\text { Crescimento, Prazer, Vigilância, } \\
\text { Estabilidade, Solidão, Recompensa, } \\
\text { Rotina, Punição, Exploração, } \\
\text { Estresse, Sobrevivência, Qualificação, } \\
\text { Carreira, Ritmo, Controle, Obediência, }\end{array}$ & 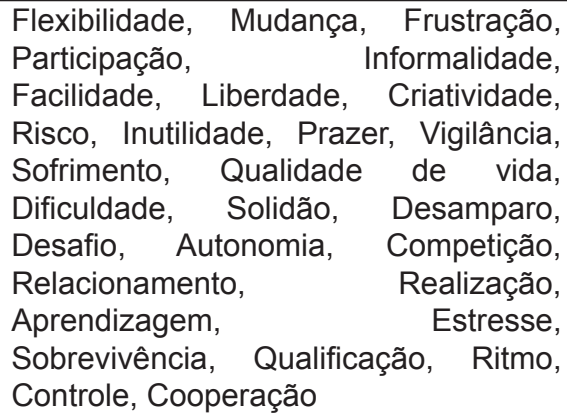 \\
\hline \multicolumn{2}{|c|}{$\begin{array}{l}\text { ALBORNOZ (2008); ANTUNES (2003A, 2003B, 2005); BENDASSOLLI (2009); } \\
\text { BORGES (1999); BOLTANSKI; CHIAPELLO (2009); BRAGA; LIMA (2007); FARIA } \\
\text { (2008); FONTENELLE (2008); GAULEJAC (2007); GURGEL (2003); HARVEY) } \\
\text { (2008); MATTOSO (1995); MENDES (2007A, 2007B); PINTO; LEMOS (2006); } \\
\text { RAMOS (2009); SENNETT (2007; 2006); TAYLOR (1986); VIEIRA; CALDAS } \\
\text { (2006) }\end{array}$} \\
\hline
\end{tabular}

Fonte: Elaboração própria (2010). 


\section{Metodologia}

A metodologia apresenta-se em duas partes: a caracterização da pesquisa, que descreve o tipo de pesquisa, a amostra e o instrumento de coleta de dados; e a operacionalização, na qual estão descritos os procedimentos adotados no tratamento e análise dos dados.

\subsection{Caracterização da pesquisa}

Do ponto de vista de seus objetivos, a pesquisa caracteriza-se como exploratório- descritiva, já que esse tipo de pesquisa, segundo Vergara (2006), expõe características de determinadas situações ou fenômenos, podendo também estabelecer correlações entre variáveis e definir sua natureza.

A população foi constituída de trabalhadores servidores públicos de uma autarquia pública estadual que passou por um vasto histórico de transformações trabalhistas desde a sua fundação, em 1955. Dessa forma, o campo da pesquisa está restrito a uma organização, configurando-a como um estudo de caso. A amostra foi composta de 146 servidores, lotados na sede da organização e nos escritórios descentralizados no interior do estado. Os servidores possuem diferentes cargos e funções sendo identificados: diretor, coordenador, técnico, gestor, assessor, auxiliar de serviços gerais e bolsistas, em ordem hierárquica. Não há nível de escolaridade definida para os cargos. O perfil dos respondentes apresenta-se com sua maioria do sexo feminino (52\%), idade entre 50 e 60 anos e tempo de serviço na instituição entre 20 e 35 anos, sendo a maior concentração nos cargos de técnico (46\%). A escolaridade que predominou entre os respondentes foi ensino médio (41\%), seguido de ensino superior completo (32\%) e, quanto ao estado civil, a maioria $(54 \%)$ é casada.

A coleta de dados ocorreu nos meses de dezembro/2009 a fevereiro/2010, através de entrega prévia e posterior recolhimento do questionário pelos pesquisadores, com contribuição dos gestores e do Setor de Recursos Humanos. A aplicação dos questionários aconteceu 
após a autorização da Diretoria Técnica da instituição. No âmbito deste estudo, optou-se pela técnica do questionário por se adequar aos objetivos do estudo, poder ser aplicado a um número elevado de pessoas, através de uma série ordenada de perguntas sem a presença do entrevistador, conforme descrito por Lakatos e Marconi (1996). $\mathrm{O}$ instrumento de pesquisa foi concebido a partir de conceitos sobre trabalho, todos extraídos do referencial teórico consultado. Foram relacionadas 44 palavras que os respondentes deveriam associar ao termo "trabalho", de acordo com a seguinte escala: "alta relação", "média relação", "indiferente ou não sei dizer", "baixa relação" e "nenhuma relação", sendo o ponto intermediário da escala o valor neutro. Antes da aplicação definitiva do questionário, foi realizado um pré-teste com sete servidores, no intuito de verificar a adequação da redação e dos termos utilizados à compreensão dos entrevistados. Isso possibilitou alterações e reformulação das questões para a aplicação definitiva do instrumento.

O tratamento dos dados ocorreu através da técnica análise fatorial, por ser uma técnica de análise multivariada que permite identificar a estrutura das inter-relações (correlações) em um grande número de variáveis definindo conjuntos de variáveis que estão fortemente interrelacionados. Com ela, tem-se o propósito de encontrar um modo de condensar a informação contida em diversas variáveis originais em um conjunto menor de novas dimensões (fatores) com perda mínima da informação (HAIR JR. et al., 2009). Para isso, utilizou-se o software SPSS (Statistical Package for the Social Sciences), versão 17.0.

Inicialmente, foi feita uma análise exploratória dos dados a fim de verificar a existência de dados perdidos (missing values) e de observações atípicas (outliers). Para evitar comprometimento do tamanho da amostra, optou-se por substituir, em vez de excluir, esses dados pela estimação da moda da variável, obtida através do SPSS. Esse método de atribuição é proposto por Rodrigues (2007, p. 38), sendo o "processo de estimação de valores perdidos com base em valores válidos de outras variáveis e/ ou observações na amostra." 


\subsection{A operacionalização da pesquisa}

A análise fatorial exploratória foi realizada seguindo os passos sugeridos por Corrar, Paulo e Dias (2009) e por Dancey e Reidy (2006), envolvendo sinteticamente as seguintes fases: cálculo da matriz de correlação, extração dos fatores e rotação dos fatores. Procedeu-se inicialmente a inspeção da matriz de correlações, a fim de verificar o pressuposto de que elas fossem suficientes para a aplicação da Análise Fatorial (HAIR JR. et al., 2009). Uma vez atendido esse pressuposto, procedeu-se os testes, tendo sido realizados inicialmente o de KaiserMeyer-Olkin (KMO) e o de esfericidade de Bartlett, tendo em vista, com o primeiro, medir o grau de correlação parcial entre as variáveis (MSA), e com o segundo, verificar se a matriz de correlação é uma matriz identidade (CORRAR; PAULO; DIAS, 2009). Em ambos os casos, os resultados foram satisfatórios, estando o KMO sempre acima de 0,7 e o teste de esfericidade de Bartlett apresentou um $p<0,000$ para o nível de significância de 0,05 , rejeitando-se, portanto, a hipótese nula de uma matriz identidade. Estes resultados indicaram a pertinência de utilização da análise fatorial.

Os pesquisadores admitiram previamente a propriedade de utilizar uma rotação oblíqua em lugar de uma rotação ortogonal, como o usual método varimax, tendo em vista a advertência de Dancey e Reidy (2006, p. 435) de que "a rotação varimax assegura que cada fator seja independente dos demais, [porém], na vida real, muitas variáveis psicológicas são intercorrelacionadas", gerando, com tal rotação, uma possível artificialidade dos dados. Então, não se estabeleceu uma independência entre os fatores como critério para interpretação do modelo final, decidindo-se pela rotação oblíqua Promax (kappa $=4)$, já que se trata do tipo de rotação em que "os pesquisadores acreditam haver relacionamento entre os fatores." (CORRAR; PAULO; DIAS, 2009, p. 90).

O método utilizado para extração dos fatores foi o dos componentes principais e os dados foram rodados no SPSS estabelecendo-se o nível mínimo de 0,4 para a carga fatorial, conforme arbítrio dos pesquisadores 
(DANCEY; REIDY, 2006). A matriz Anti-image foi verificada, visto que analisa a relação de uma variável contra as outras; e também as comunalidades foram observadas, a fim de identificar o percentual de explicação que cada variável obteve pela análise fatorial (CORRAR; PAULO; DIAS, 2009).

Todos os casos de cross-loadings foram analisados e retiradas as variáveis com especificação cruzada, uma a uma, gerando a exclusão de vinte e sete delas, a saber: tranquilidade, padronização, autonomia, estresse, informalidade, cooperação, frustração, segurança, proteção, risco, sobrevivência, criatividade, inutilidade, competição, repetição, liberdade, sofrimento, crescimento, dificuldade, aprendizagem, participação, prazer, estabilidade, qualificação, hierarquia, rotina e mudança. O modelo resultante, com dezessete variáveis, dispostas em seis fatores, é apresentado no Quadro 2.

Quadro 2 - Matriz incompleta dos fatores (coeficientes > 0,04, após rotação)

\begin{tabular}{|l|c|l|l|l|l|l|}
\hline Variáveis & $\begin{array}{c}\text { Fator } \\
\mathbf{1}\end{array}$ & Fator 2 & Fator 3 & Fator 4 & Fator 5 & Fator 6 \\
\hline Realização &, 854 & & & & & \\
\hline Desafio &, 792 & & & & & \\
\hline Vocacao &, 741 & & & & & \\
\hline Flexibilidade &, 492 & & & & & \\
\hline Qualidade Vida & &, 867 & & & & \\
\hline Carreira & &, 807 & & & & \\
\hline Recompensa & &, 759 & & & & \\
\hline Desamparo & & &, 923 & & & \\
\hline Solidão & & &, 803 & & & \\
\hline Exploracao & & &, 615 & & & \\
\hline Obediência & & & &, 880 & & \\
\hline Controle & & & &, 812 & & \\
\hline Ritmo & & & &, 674 & & \\
\hline Vigilância & & & & &, 849 & \\
\hline Punição & & & & &, 706 & \\
\hline Facilidade & & & & & &, 835 \\
\hline Relacionamento & & & & & &, 786 \\
\hline
\end{tabular}

Fonte: dados da pesquisa (2010). 
Após a geração desse modelo, os pressupostos e principais testes foram novamente checados, chegando-se aos seguintes resultados: KMO de 0,700; o teste de esfericidade de Bartllet obteve um $p<0,000$ para o nível de significância de 0,05; com a matriz de anti-imagem, foram obtidas combinações com correlação superior a 0,50 para cada par de variáveis; todas as comunalidades ficaram acima de 0,60 e se atingiu $69 \%$ de variância explicada com o modelo.

Com relação à confiabilidade dos fatores, os valores de consistência interna (coeficientes alpha de Cronbach) variaram entre 0,60 e 0,81, com exceção do sexto fator, que ficou com 0,33 (primeiro fator, 0,74 ; segundo fator, 0,81 ; terceiro fator, 0,73 ; quarto fator, 0,75 ; quinto fator, 0,60 ; sexto fator, 0,33). Em pesquisas exploratórias, Hair et al. (2009) consideram admissível um alfa com valores a partir de 6 . Do ponto de vista da estabilidade do instrumento para futuras pesquisas, o fator 6 deve ser visto com ressalva. No entanto, considerando sua relevância e ligação teórica com os outros fatores, no contexto da presente pesquisa o fator não pôde ser desconsiderado, já que é importante fonte de iluminação para os resultados.

\section{Resultados}

Os fatores foram nomeados conforme apresentado no Quadro 3. Os conteúdos semânticos dos termos componentes de cada fator são sintetizados no Quadro 4.

Quadro 3 - Composição de variáveis por fator

\begin{tabular}{|l|c|c|c|c|c|}
\hline $\begin{array}{l}\text { Dimensões } \\
\text { do trabalho } \\
\text { flexível }\end{array}$ & $\begin{array}{c}\text { Dimensões } \\
\text { do trabalho } \\
\text { satisfatório e } \\
\text { compensador }\end{array}$ & $\begin{array}{c}\text { Dimensões } \\
\text { indesejadas } \\
\text { no trabalho }\end{array}$ & $\begin{array}{c}\text { Dimensões } \\
\text { do trabalho } \\
\text { tradicional }\end{array}$ & $\begin{array}{c}\text { Dimensões } \\
\text { do controle } \\
\text { no trabalho } \\
\text { tradicional }\end{array}$ & $\begin{array}{c}\text { Dimensões } \\
\text { do controle no } \\
\text { trabalho flexivel }\end{array}$ \\
\hline $\begin{array}{l}\text { Realização } \\
\text { Desafio } \\
\text { Vocação } \\
\text { Flexibilidade }\end{array}$ & $\begin{array}{c}\text { Qualidade de } \\
\text { vida } \\
\text { Carreira } \\
\text { Recompensa }\end{array}$ & $\begin{array}{c}\text { Desamparo } \\
\text { Solidão } \\
\text { Exploração }\end{array}$ & $\begin{array}{c}\text { Obediência } \\
\text { Controle } \\
\text { Ritmo }\end{array}$ & $\begin{array}{c}\text { Vigilância } \\
\text { Punição }\end{array}$ & $\begin{array}{c}\text { Facilidade } \\
\text { Relacionamento }\end{array}$ \\
\hline
\end{tabular}

Fonte: elaboração própria (2010). 


\section{Quadro 4 - Glossário dos termos/variáveis componentes dos fatores}

\begin{tabular}{|c|c|}
\hline Variáveis & Significado \\
\hline Realização & $\begin{array}{l}\text { ato ou efeito de realizar-se; aquilo que se põe em prática e se } \\
\text { consegue realizar com esforço. }\end{array}$ \\
\hline Desafio & $\begin{array}{l}\text { ato ou processo de desafiar, podendo ser tomado em dois sentidos: } \\
\text { (i) chamamento para qualquer modalidade de competição; (ii) ato } \\
\text { de incitar alguém para que faça algo, geralmente além de suas } \\
\text { possibilidades. }\end{array}$ \\
\hline Vocação & $\begin{array}{l}\text { disposição natural ou propensão, traz consigo a ideia de "uma } \\
\text { disposição natural e espontânea que orienta uma pessoa no sentido de } \\
\text { uma atividade"; trata-se de uma propensão individual. }\end{array}$ \\
\hline Flexibilidade & $\begin{array}{l}\text { trata-se de uma característica ou qualidade do que é flexível e } \\
\text { maleável. Envolve facilidade e ligeireza de movimentos, agilidade, } \\
\text { elasticidade. Por derivação de sentido pode significa uma característica } \\
\text { de quem é compreensível. }\end{array}$ \\
\hline $\begin{array}{l}\text { Qualidade de } \\
\text { vida }\end{array}$ & $\begin{array}{l}\text { gestão dinâmica e contingencial de fatores físicos, tecnológicos } \\
\text { e sociopsicológicos que afetam a cultura e renovam o clima } \\
\text { organizacional, refletindo-se no bem-estar do trabalhador e na } \\
\text { produtividade das empresas. }\end{array}$ \\
\hline Carreira & $\begin{array}{l}\text { termo que vem do latim carrarì, que significa 'caminho para carros' } \\
\text { e carrega um sentido de continuidade, de "profissão que oferece } \\
\text { oportunidades de progresso ou em que há promoção" }\end{array}$ \\
\hline Recompensa & $\begin{array}{l}\text { favor, presente com que se mostra reconhecimento por um obséquio, } \\
\text { por uma boa ação; retribuição, prêmio. Em sentido jurídico: pagamento } \\
\text { que corresponde à promessa feita no sentido de retribuir aquele que } \\
\text { conseguisse determinado resultado. }\end{array}$ \\
\hline Desamparo & $\begin{array}{l}\text { está ligado à falta de proteção, de ajuda, à sensação de abandono, } \\
\text { solidão. }\end{array}$ \\
\hline Solidão & $\begin{array}{l}\text { estado de quem se acha ou se sente desacompanhado ou só; } \\
\text { isolamento; sensação ou situação de quem vive afastado do mundo ou } \\
\text { isolado em meio a um grupo social. }\end{array}$ \\
\hline Exploração & $\begin{array}{l}\text { proveito obtido de maneira ilícita ou destituído de ética, ato de tirar } \\
\text { partido de, abuso da boa-fé ou da situação especial de alguém. }\end{array}$ \\
\hline Obediência & $\begin{array}{l}\text { submissão completa; sujeição, vassalagem; esfera de autoridade ou de } \\
\text { jurisdição. }\end{array}$ \\
\hline Controle & $\begin{array}{l}\text { monitoração, fiscalização ou exame minucioso, que obedece a } \\
\text { determinadas expectativas, normas, convenções; capacidade de reagir } \\
\text { de imediato em determinadas situações. }\end{array}$ \\
\hline Ritmo & $\begin{array}{l}\text { movimento regular e periódico no curso de qualquer processo; } \\
\text { cadência. }\end{array}$ \\
\hline Vigilância & $\begin{array}{l}\text { estado de quem permanece alerta, de quem age com precaução para } \\
\text { não correr risco; cuidado. }\end{array}$ \\
\hline Punição & algo penoso ou desagradável que alguém é obrigado a suportar. \\
\hline Facilidade & $\begin{array}{l}\text { característica do que se faz sem dificuldade; ausência de obstáculos } \\
\text { ou dificuldades; disposição natural; aptidão, dom; demonstração de } \\
\text { perícia; destreza, prontidão. }\end{array}$ \\
\hline Relacionamento & $\begin{array}{l}\text { capacidade de manter relacionamentos, de conviver bem com seus } \\
\text { semelhantes; familiaridade }\end{array}$ \\
\hline
\end{tabular}

Fonte: elaboração própria a partir de consulta a Houaiss (2001) e Fernandes (1996). 
O fator 1 é composto pelas variáveis realização, desafio, vocação e flexibilidade. Este primeiro fator congrega variáveis que guardam grande relação com as dimensões que a literatura associa ao trabalho sob o paradigma da flexibilidade. Assim, foi nomeado como "dimensões do trabalho flexível". Checando-se as medidas de tendência central, constata-se que os respondentes atribuem alta relação destas variáveis com a categoria trabalho indicando que as mesmas compõem os principais elementos do quadro conceitual destes sujeitos, no que se refere ao tema trabalho, na contemporaneidade.

Flexibilidade parece indicar uma característica que os chamados trabalhadores flexíveis devem possuir, convergente à visão de um eu maleável, capaz de dobrar-se, adaptar-se, para isso investindo em processos de permanente ação e criação dadas as demandas que se apresentam (FONTENELLE, 2008, SENNETT, 2006). Nesse sentido, realização e desafio são variáveis que ganham relevância ao serem entendidas como ato ou processo, isto é, aquilo que indica uma ação intencional do indivíduo, um contínuo mover-se, um dirigir-se com esforço para algo. Essas variáveis ecoam o discurso flexível que defende a necessidade de proatividade do trabalhador, onde a participação é apregoada como a nova base das relações de trabalho, em substituição à passividade do trabalhador outrora limitado pelas imposições da autoridade hierárquica e do confinamento dos cargos. Estando o novo trabalhador condicionado a um contínuo movimentar-se, as diversas situações de mudanças são individualmente e coletivamente encaradas como desafios a vencer, imbricado na cultura da conquista (GAULEJAC, 2007). Por outro lado, a variável vocação parece ir na contramão do discurso da flexibilidade, uma vez que este não traz a marca da garantia, para o trabalhador, de envolver-se somente com atividades para as quais se sinta "naturalmente" vocacionado. Sob a lógica da flexibilidade, trata-se de estar disponível para adequar-se rapidamente ao que se apresenta, incentivando o surgimento de um "trabalhador genérico", capaz de atuar em tantos ramos quantos necessários à manutenção de sua empregabilidade (BOLTANSKI; CHIAPELLO, 2009; SENNETT, 2007), e não ao exercício de uma vocação. 
Entretanto, quando as variáveis componentes das "dimensões do trabalho flexível" são tomadas em conjunto, e nelas incluída a variável "vocação", pode-se inferir que esse fator corrobora com as compreensões de Batista-dos-Santos, Albandes-Moreira e Freitas (2006) e de Nepomuceno (2005), segundo as quais as organizações contemporâneas, sob o paradigma da flexibilidade, apresentamse metaforicamente para o sujeito trabalhador como espécies de organizações-escola, constituindo-se como instâncias de permanente formação do trabalhador, devendo este se portar como um trabalhadoraluno do qual se requer uma postura sempre flexível, com permanente busca de realização e propensão para assumir desafios, cuja vocação se traduz em propensão ou disposição natural para portar-se dessa forma, visando a atender às demandas da hora.

O fator 2 foi nomeado como "dimensões do trabalho satisfatório e compensador", sendo composto pelas variáveis "qualidade de vida, carreira e recompensa". As medidas de tendência central indicam que a maioria dos respondentes estabelece alta relação dessas variáveis com o trabalho.

Embora o tema da qualidade de vida não seja novo, estando em geral relacionado ao bem estar e satisfação física e emocional no trabalho, sua emergência e difusão acelerada como objeto de consultoria empresarial, ensino e pesquisas acadêmicas, é fenômeno recente, colocando-se como mais uma dentre as ferramentas de gestão contemporânea (VASCONCELOS, 2001). Qualidade de vida é um tema que emerge, na atualidade, com grande força, na tentativa de "equilibrar" as ansiedades originárias do trabalho, ao mesmo tempo em que visa a garantir a produtividade do trabalho (Fernandes, 1996). Ressalte-se que o campo da pesquisa se trata de uma organização em que um programa de QVT fora implantado, com grandes repercussões como modelo de QVT para organizações públicas sob o ideário da nova gestão pública. Os respondentes parecem atribuir grande valor à qualidade de vida, associando-a à busca de satisfação no trabalho o que parece guardar relação com a lógica de ganhos e recompensas, presentes ou futuros, que as variáveis carreira e recompensa também evocam. 
O tema da carreira, sob o atual discurso da flexibilidade, tem sido tratado num sentido contrário à etimologia do termo (ver Quadro 4), pois as ideias de continuidade e progressão têm sido substituídas pela lógica da instabilidade e incerteza, que impossibilitam as perspectivas de uma progressão associada à ascensão em uma escala hierárquica, promoções e benefícios crescentes, tornando fluidos os conceitos de mercado de trabalho e sucesso profissional (LACOMBE, 2002). Porém, não parece ser o caso deste grupo de respondentes dado o tipo de organização e vínculo empregatício. Nesse contexto, a variável carreira pode estar relacionada ao desejo desses trabalhadores de poderem construir uma história de trabalho duradoura e igualmente recompensadora dentro desta organização. Semelhantemente, a valorização da variável recompensa também evoca a ideia de algo que se espera, para agora ou para o futuro, como fruto do esforço e dos resultados alcançados.

Tomadas em conjunto, as variáveis componentes do fator 2 (qualidade de vida, carreira e recompensa) exemplificam uma espécie de economia de troca entre o indivíduo e a organização, pela mediação do trabalho. Os sujeitos veem a própria organização como meio para segurança, material e psicológica, através do trabalho. A organização do trabalho precisa Ihes conferir satisfação e compensação, enquanto eles entregam esforço e resultados:

como toda comunidade humana, a organização é regida por regras não escritas que organizam as trocas entre os indivíduos e os grupos. [...] O sentimento de segurança no trabalho está fundado sobre contratos implícitos, como a promessa de poder progredir na hierarquia ou de ter aumentos de salários ao envelhecer. Os contratos implícitos têm uma função crucial: criar uma economia de parceria. (GAULEJAC, 2007, p. 158)

Para Gaulejac (2007), a ausência dessa economia de parceria, à qual se assiste na atualidade, tem gerado um quadro perverso em que indivíduos são abandonados a si mesmos, como exemplificam as variáveis integrantes do fator 3 . 
O fator 3 é uma espécie de antítese do fator 2 por agregar variáveis (desamparo, solidão e exploração) que podem ser entendidas conjuntamente como dimensões indesejadas no trabalho. Em conjunto, essas variáveis estão ligadas a sentimentos nocivos (desamparo e solidão) e ao contexto ambiental (exploração). De maneira geral, as medidas de tendência central referentes a esse fator indicam que a maior parte dos respondentes percebe baixa relação entre os "sentimentos insalubres" e o trabalho, ratificando sua rejeição aos mesmos. Apenas a variável exploração situa-se numa "zona de incerteza", como será adiante discutido.

Analisando-se a relação entre os termos que compõem o fator, as variáveis "desamparo" e "solidão" emergem como conceitos relacionados a emoções negativas, e ligadas a sintomas de depressão (GLINA, 2001). Quanto ao desamparo, Sennett (2007) e Gaulejac (2007) afirmam que a flexibilidade, à medida que combate a rigidez e faz crescer o individualismo, deixa nos trabalhadores a sensação de estarem "à deriva", expostos a riscos, desamparados. Esses termos conectam-se de maneira análoga a consequências indesejadas da racionalização do trabalho a partir da fase tradicional do capitalismo, e estendem-se aos sentimentos nocivos causados pela flexibilidade.

A lógica da flexibilidade no ambiente de trabalho impossibilita os relacionamentos de longo prazo, tendo em vista que as equipes flexíveis são de curta duração, ou tem a longevidade de um projeto. Esses elementos, aliados à alta competitividade semeada entre os trabalhadores dentro das equipes, leva a uma precarização dos laços sociais. Quando não há possibilidades de se estabelecerem relacionamentos de longo prazo entre os pares, não há formação de laços. A variável solidão emerge ligada ao sentimento negativo vinculado a uma ordem onde impera o individualismo (BOLTANSKI; CHIAPELLO, 2009, SENNETT, 2007).

Em geral, a variável "exploração" tem seu significado vinculado ao trabalho a partir do capitalismo tradicional, quando o ritmo e a intensidade do trabalho são altos, e o controle sobre o processo de trabalho sai das 
mãos do trabalhador. Esse grupo de respondentes parece estar dividido quanto a estabelecer muita ou pouca relação da variável exploração com o trabalho, estando as frequências polarizadas entre alta e média relação (46\% dos respondentes) e baixa e nenhuma relação (45\% dos respondentes). Essa variável parece ser fonte de incerteza para os sujeitos. Uma possibilidade da incerteza em torno desta variável é a situação ocupacional do grupo de respondentes como servidores de uma organização pública, instância em que temas como estes não são tão diretamente associados ao trabalho, diferentemente das organizações privadas em que o conflito capital-trabalho põe em maior evidência as situações históricas de exploração do trabalho pelo capital.

O fator 4 se apresenta como uma espécie de par antagônico do fator 1 , por ser composto por variáveis (obediência, controle e ritmo) que são frequentemente associadas a características do trabalho sob o capitalismo tradicional (Faria, 2008; Harvey, 2008; Sennett, 2007). Assim, foi nomeado como "dimensões do trabalho tradicional". Em sua maioria, os respondentes estabeleceram média e alta relação dessas variáveis com o trabalho.

Obediência, controle e ritmo eram aspectos amplamente valorizados no contexto do trabalho exercido sob o binômio taylorismofordismo, em que a busca pela racionalização e padronização dos processos implicava numa aceleração do ritmo de trabalho tendo em vista os ganhos de escala. No geral, a intensificação do ritmo e volume do trabalho implicavam em problemas de desgaste físico e psicológico do trabalhador, derivando para doenças ocupacionais. Atualmente, o ritmo emerge associado à cultura das mudanças velozes e constantes que imperam sob a lógica flexível da excelência e do desempenho que, para Mendes (2007b), tem implicado na patologia da sobrecarga:

Considera-se que a patologia da sobrecarga está articulada ao jogo de dominação social regido pela ideologia da excelência e do desempenho, e pode ter nas suas origens a disciplina da fome e a centralidade do trabalho. [...] A centralidade do trabalho pode levar o trabalhador, pela necessidade de realização e 
reconhecimento, elementos nucleares para a identidade, subjetividade e emancipação, a considerar que todas as oportunidades devem ser aproveitadas, usando seu talento e competência intensamente, o que pode implicar uma expropriação e exploração do trabalho pela aceitação das demandas que vão além das suas condições físicas, psicológicas e sociais. (MENDES, 2007b, p. 55)

Tanto o ritmo quanto a intensificação do trabalho, sob o capitalismo tradicional, eram alcançados por meio de sistemas de gestão e por uma estrutura organizacional que garantiam o controle, por parte da administração, e a obediência, do lado do trabalhador. Atualmente, segundo Faria (2008), as formas de controle se modificaram e não se mostram de todo discerníveis, o que implica que a obediência também não se manifesta da mesma maneira que se dava, por exemplo, sob a lógica da supervisão taylorista. Tanto ações personalísticas, como o poder de persuasão de líderes visionários sobre suas equipes de trabalho, quanto estratégias impessoais, como exemplificam os sistemas de gestão integrada via tecnologia da informação, são manifestações das formas atualizadas de emergência do binômio controle-obediência. Tomadas em conjunto, as variáveis componentes do fator 4 apontam para as novas expressões fenomênicas de aspectos ligados ao capitalismo tradicional.

O fator 5 aloca duas variáveis que guardam entre si alta relação teórica no contexto da racionalização do processo de trabalho: vigilância e punição. Tanto a vigilância quanto a punição configuram instrumentos do controle disciplinar, que atua sobre o tempo e os corpos dos indivíduos (FOUCAULT, 1997) ou, usando a linguagem da administração científica, o controle do processo de trabalho, sobre os tempos e movimentos dos trabalhadores (TAYLOR, 1986). A palavra vigilância está ligada ao "ato de velar, de estar atento" (HOUAISS, 2001).

Na busca pela racionalização do trabalho, quando Taylor (1986) desagregou a concepção do processo de trabalho da sua execução, surgiu a figura do supervisor (aquele que vê acima de). A "super-visão" 
está ligada à atividade de vigiar a execução das atividades, e à função de controle atribuída ao administrador (FAYOL, 1981). O papel da punição nesse mecanismo é o de reprimir comportamentos que fogem às normas e aos padrões estabelecidos como "a melhor forma" de executar as tarefas. Apesar de também presentes no contexto de trabalho flexível, a vigilância e a punição se ligaram ao processo de trabalho a partir da racionalização do trabalho no capitalismo tradicional. Por essa razão, o fator foi nomeado como dimensões de controle no trabalho tradicional.

No contexto da pesquisa, os respondentes dividem-nas entre os que percebem baixa relação e média relação das variáveis vigilância e punição com o trabalho. Uma provável explicação para tal nível de associação é o vínculo estabelecido entre os trabalhadores e a organização na qual foi realizada a pesquisa. Por tratar-se de uma instituição pública, cuja lógica de resultados está voltada à coletividade, as relações de dominação ou são esmorecidas, ou ilegíveis.

O fator 6 , formado pelas variáveis facilidade e relacionamento, foi nomeado como dimensões de controle no trabalho flexível, sendo complementar ao fator 5 . Apesar de ter sido no capitalismo tradicional que houve a cooptação do saber do trabalhador, é no capitalismo flexível que a facilidade, aliada principalmente à automação, se configura como uma dimensão de controle dos trabalhadores. No mundo flexível, o alto nível de especialização, intensificado pela tecnologia, torna o trabalho mais simples e fácil, e fraca a identificação dos trabalhadores com suas funções. Desestimula-se a busca por qualificação específica ao exercício de um ofício, reflexo extremo da perda do controle do processo de trabalho pelo trabalhador (SENNETT, 2007).

A habilidade de relacionar-se está entre os atributos mais requisitados para os trabalhadores no contexto do trabalho flexível. A gestão das relações humanas baseia-se nas habilidades dos líderes em manter o controle sobre o processo de trabalho sem que haja resistência por parte dos trabalhadores. Da mesma forma que o taylorismo focava em impor regras fixas sobre os movimentos, os conceitos de equipes e times, oriundos da lógica da flexibilidade, focam o monitoramento 
e o adestramento de atitudes, pelas vias da participação e dos "relacionamentos". Assim, o foco de controle migrou do adestramento dos corpos ao controle das mentes (BOYNE, 2000), emoções e relações.

Os respondentes da pesquisa estabelecem média relação de seu trabalho com a variável facilidade (53\% dos respondentes) e alta relação com a variável "relacionamento" (64\% dos respondentes). Esse fato parece indicar que, mesmo em uma organização pública, as dimensões do controle no trabalho flexível encontram-se fortemente associadas ao cotidiano dos trabalhadores.

\subsection{Síntese dos fatores}

Vistos em conjunto, os seis fatores parecem indicar um hibridismo nas relações que os respondentes estabelecem entre as variáveis e o trabalho, ora tendendo a ressaltar relações com as dimensões flexíveis, ora apontando uma relação significativa com variáveis que remontam ao trabalho sob o capitalismo tradicional. Assim, a escolha pela rotação oblíqua se mostrou adequada, podendo-se verificar a inter-relação dos fatores, muitas vezes emergente de maneira antagônica. Esses antagonismos só se tornam compreensíveis quando se tem em vista que as concepções dos sujeitos a respeito do trabalho, não se dão de maneira estanque e linear, mas de maneira dinâmica e contraditória, em face de sua inscrição nas organizações do trabalho que são, como propõe Faria (2008, p. 27), "construções sociais e históricas, complexas, dinâmicas e contraditórias, nas quais convivem estruturas formais e culturais, manifestas e ocultas, concretas e imaginárias." Então, as concepções de trabalho emergem neste movimento.

Tendo isso em vista, os processos de transição, como os ora apregoados na literatura e vivenciados por muitos no contexto do mundo do trabalho, não se dão numa sequência de fatos históricos isolados, mas com a intensidade da dinâmica social, cujos processos de subjetivação (do trabalhador) sofrem a mediação do social numa perspectiva micro (a organização do trabalho) e macro (a sociedade), em que cada sujeito ou grupo de sujeitos tende a significar tais mudanças de maneira peculiar. 
Por exemplo, esse grupo de respondentes tende a amalgamar passado e presente, tradição e flexibilidade numa tentativa de novas sínteses para suas existências profissionais.

Levando-se em conta o contexto organizacional em que estão inseridos, isto é, uma organização pública, essa metáfora do amálgama, ou da mescla, tende a se tornar mais expressiva para esses sujeitos em suas respostas, especialmente no que toca à emergência significativa das dimensões ligadas à lógica corrente da flexibilidade. Esses resultados parecem indicar o potencial de mudança nas perspectivas de trabalho de servidores públicos, fato que possivelmente se deve pela difusão da lógica gerencialista que a chamada nova gestão pública tem fomentado.

\section{Considerações finais}

Nesta última seção, o trabalho avalia, em forma de considerações finais, dois aspectos igualmente importantes: o aspecto conteudístico (ou teórico) e o metodológico.

Quanto ao aspecto teórico, pode-se afirmar que o objetivo proposto para a pesquisa, isto é, o de identificar as dimensões que um grupo de trabalhadores associa ao trabalho, na contemporaneidade, não somente foi atingido como também permitiu discutir as peculiaridades da emergência dessas dimensões, num contexto também peculiar, o da organização e gestão pública. Os resultados permitiram refletir sobre as mudanças nas concepções de trabalho de servidores públicos face à visão gerencialista que tem sido propagada nas últimas décadas, no contexto das organizações públicas.

Além disso, o que este texto chamou de "metáfora do amálgama" contribui com a reflexão teórica, e suas implicações pragmáticas, no sentido da busca de uma melhor compreensão a respeito dos processos de mudança social, como os ora vivenciados, em que dimensões estruturantes da vida em sociedade, como o trabalho, sofrem "abalos" que implicam em consequências, especialmente para o trabalhador, em sua saúde, subjetividade e moralidade. Estas devem ser consideradas 
especialmente na esfera da gestão. Uma reflexão possível, também ligada ao amalgamento evidenciado nos dados, diz respeito ao que ou ao quanto se conserva da tradição no que hoje se chama de flexível, devendo-se tentar apreender o que/quanto do "velho" se conserva no "novo", sob novas aparências ou simulacros.

No que se refere aos aspectos metodológicos, entende-se que a pesquisa de campo e a análise que lhe sucedeu permitiram ensejar conclusões quanto à pertinência e limitações do estudo. A técnica da análise fatorial se mostrou plenamente favorável ao alcance do objetivo proposto para o trabalho. A escolha pela rotação oblíqua também se mostrou pertinente para uma maior compreensão da complexidade do objeto elegido para estudo. Quanto ao instrumento utilizado, a exclusão de vinte e sete variáveis, durante a fase de análise dos dados, mostra que o modelo inicial do instrumento não foi validado neste grupo de respondentes. Porém, o exercício de enxugamento do modelo que tal análise propiciou, constitui-se uma contribuição desta pesquisa para futuros estudos que almejem validar o instrumento reformulado, aplicando-o a outras amostras. Ainda, sugere-se que o instrumento seja replicado em novos estudos no contexto de organizações públicas, mas também no contexto de organizações privadas em que a dinâmica capital-trabalho pode ser apreendida de maneira mais direta e, assim, revelar facetas das mudanças em curso, sob o capitalismo flexível.

Finalmente, entende-se que este trabalho socializa resultados que permitem um avanço na discussão teórico-empírica sobre o contraditório, multifacetado e instigante mundo do trabalho, pois, como afirma Gadotti (2006, p. 48): "admitindo-se que o homem se realiza pelo trabalho, também temos de admitir que ele pode perder-se nele."

\section{Referências}

AKTOUF, O. Pós globalização, administração e racionalidade econômica: a Síndrome do Avestruz. São Paulo: Atlas, 2004. 
ALBORNOZ, S. O que é trabalho. São Paulo: Editora Brasiliense, 2008. (Coleção Primeiros Passos).

ANTUNES, R. O caracol e sua concha: ensaios sobre a nova morfologia do trabalho. São Paulo: Bomtempo, 2005

. Os Sentidos do Trabalho: ensaio sobre a afirmação e a negação do trabalho. São Paulo: Bomtempo, 2003a.

Adeus ao trabalho? ensaio sobre a metamorfose e a centralidade do mundo do trabalho. (9 ed.) São Paulo: Cortez, 2003b

ARENDT, H. A condição humana. 7. ed. Rio de Janeiro: Forense Universitária, 1995.

BATISTA-DOS-SANTOS, A.C.; ALBANDES-MOREIRA, L.A.; FREITAS, A. A. F. Reflexão Crítica das Representações de Organização e Administração de um Grupo de Proprietários-Gerentes e de um Grupo de Professores de Administração: um Estudo Teórico-Empírico. In: ENCONTRO DE ESTUDOS ORGANIZACIONAIS (ENEO), 2006, Porto Alegre. Anais..., Porto Alegre: ANPAD, 2006. p. 1-17.

BATISTA-DOS-SANTOS, A.C.; ALBANDES-MOREIRA, L.A.; NEPOMUCENO, L.H. Mentira ou verdade ? Uma Abordagem Crítica da Conceptualização de Organização que Faz um Grupo de Micro, Pequenos e Médios Empresários na cidade de Fortaleza: um Estudo Exploratório. In: ENCONTRO DE ESTUDOS SOBRE EMPREENDEDORISMO E GESTÃO DE PEQUENAS EMPRESAS, IV, 2005, Curitiba. Anais..., Curitiba: EGEPE, 2005. p. 1184-1198.

BAUMAN, Z. Modernidade líquida. Rio de Janeiro: Jorge Zahar Ed., 2001.

BENDASSOLLI, P.F. Psicologia e trabalho: apropriações e significados. São Paulo: Cengage Learning, 2009. (Coleção Debates em Administração).

BOLTANSKI, L.; CHIAPELLO, E. O Novo Espírito do Capitalismo. São Paulo: Editora WMF Martins Fontes, 2009. 
BORGES, L. O. As concepções do trabalho: um estudo de análise de conteúdo de dois periódicos de circulação nacional. Revista de Administração Contemporânea (RAE), Curitiba, v.3, n.3, p.81-107, set-dez, 1999.

BOYNE, R. Post-Panopticism. Economy and Society. v. 29, n.2, p. 285307, may, 2000. Disponível em: <http://www.tandfonline.com/doi/abs/1. 1080/030851400360505?queryID=\%24\{resultBean.queryID\}\#preview> Acesso em: 02/02/2013.

BRAGA, C.D.; LIMA, I.L.C. Transformações na Função Gerencial: a percepção dos Gestores de Recursos Humanos sobre o papel do gerente contemporâneo. In: ENCONTRO DE GESTÃO DE PESSOAS E RELAÇÕES DE TRABALHO (ENGPR), I, 2007, Natal, Anais... Natal: ANPAD, 2007. 1CD ROM.

BRESSER-PEREIRA, L.C. Democracia, Estado Social e Reforma Gerencial. Revista de Administração de Empresas. São Paulo, v. 50, n.1, p. 112-116, jan./mar. 2010. Seção Pensata.

CHESNAIS, F. A Mundialização do Capital. São Paulo: Scrita, 1996.

CLEGG, S. R.; HARDY, C. Organização e Estudos Organizacionais. In: CLEGG, S.R.; HARDY, C.; NORD, W. (Orgs.). Handbook de Estudos Organizacionais, v. 1. São Paulo: Atlas, 1998. p. 27-57.

CODO; W.; SORATTO, L.; VASQUES-MENEZES, I. Saúde mental e trabalho. In: ZANELLI, J.E.B.A; BASTOS, A.V.B. (orgs.). Psicologia, organizações e trabalho no Brasil. Porto Alegre: Artmed, 2004, p. 276-299.

CORRAR, L.J; PAULO. E; DIAS FILHO,J. M. Análise Multivariada para os cursos de Administração, Ciências Contábeis e Economia. Fundação Instituto de Pesquisas Contábeis, Atuariais e Financeiras (FIPECAFI): São Paulo: Atlas, 2009.

DANCEY, C. P.REIDY, J.. Trad. Lorí Viali. Estatística sem matemática para Psicologia usando SPSS para Windows. 3. ed. Porto Alegre: Artimed. Bookman, 2006. 
FARIA, J. H. Economia política do poder: fundamentos. v. 1. Curitiba: Juruá, 2008.

FAYOL, H. Administração Industrial e Geral: previsão, organização, comando, coordenação, controle. São Paulo: Atlas, 1981.

FONTENELLE, I.A. Pós-modernidade: trabalho e consumo. São Paulo: Cengage Learning, 2008. (Coleção Debates em Administração).

FOUCAULT, M. Vigiar e Punir. 16. ed. Petrópolis: Vozes, 1997.

GADOTTI, M. Concepção dialética da educação. São Paulo: Cortez, 2006

GAULEJAC, V. Gestão como doença social: ideologia, poder gerencialista e fragmentação social. São Paulo: Idéia e Letras, 2007

GLINA, D.M.R. et al . Saúde mental e trabalho: uma reflexão sobre o nexo com o trabalho e o diagnóstico, com base na prática. Cad. Saúde Pública, Rio de Janeiro, v. 17, n. 3, Junho 2001.

GORZ, A. Metamorfoses do Trabalho: Crítica da razão econômica. São Paulo: Annablume: 2003.

GURGEL, C. A Gerência do Pensamento: gestão contemporânea e consciência neoliberal. São Paulo: Cortez, 2003.

HAIR, J.F, Jr.; BLACK, W.C.; BABIN, B.J.; ANDERSON, R.E.; TATHAN, R.L. Análise Multivariada de Dados. 6 ed. Porto Alegre: Bookman, 2009.

HARVEY, D. Condição Pós-Moderna. São Paulo: Edições Loyola, 2008.

HOUAISS, A. Dicionário Eletrônico Houaiss. Rio de Janeiro: Objetiva, 2001. 1CD-ROM.

LACOMBE, B.M.B. O Aluno de Administração de Empresas, o Trabalho e a Construção da Carreira Profissional: Contribuições de um Estudo na Grande São Paulo. In: ENCONTRO ANUAL DA 
ASSOCIAÇÃO NACIONAL DOS CURSOS DE PÓS-GRADUAÇÃO EM ADMINISTRAÇÃO (ENANPAD). 26, Salvador, Anais... Salvador: ANPAD, 2002, 1CD ROM.

LAKATOS, E.M.; MARCONI, M.A. Metodologia do trabalho científico. 2. ed. São Paulo: Atlas, 1996.

MADUREIRA, C.; RODRIGUES, M. A Administração Pública do século XXI: aprendizagem organizacional, mudança comportamental e reforma administrativa. Comportamento Organizacional e Gestão. Lisboa, v. 12, n. 2, p. 153-171, 2006. Disponível em:<http://www.scielo.gpeari. mctes.pt/scielo.php?script=sci_arttext\&pid=S087296622006000200002 \&lng=pt\&nrm=iso>. Acesso em 02/02/2013.

MATTOSO, J. A desordem do trabalho. São Paulo: Editora Página Aberta, 1995.

MENDES, A.M. Da psicodinâmica à psicopatologia do trabalho. In: MENDES, A.M. (org.) Psicodinâmica do trabalho: teoria, método e pesquisas. São Paulo: Casa do Psicólogo, 2007a. p. 29-48

Novas formas de organização do trabalho, ação dos trabalhadores e patologias sociais. In: MENDES, A.M. (org.) Psicodinâmica do trabalho: teoria, método e pesquisas. São Paulo: Casa do Psicólogo, 2007b. p. 49-61

MORIN, E.M.; TONELLI, M.J.; PLIOPAS, A.L. V. O Trabalho e seus sentidos. Psicologia e Sociedade, Porto Alegre, v.19, n. spe, p.4756, 2007. Disponível em:< http://www.scielo.br/scielo.php?script=sci_ arttext\&pid=S0102-71822007000400008\&lng=en\&nrm=iso>. Acesso em 02/02/2013

NEPOMUCENO, L.H. Processo Ensino-Aprendizagem em uma média empresa desde o ponto de vista da teoria crítica. 2005, $126 \mathrm{f}$. Dissertação (Mestrado em Educação)-Universidade Estadual do Ceará, Fortaleza: UECE, 2005.

OFFE, C. Trabalho: a categoria-chave da Sociologia? Revista Brasileira de Ciências Sociais, São Paulo, v.4, n.10, p.1-27, jun, 1989. 
OSÓRIO, F.M. Novos rumos da gestão pública brasileira: dificuldades teóricas ou operacionais? Revista Eletrônica sobre a Reforma do Estado (ReRE), Salvador, v.1 n. 1, mar./abr./maio, 2005.

PINTO, M.C.S.; LEMOS, A.H.C. Empregabilidade dos Administradores: Quais os Perfis Profissionais que vêm sendo Demandados pelas Empresas? In: Encontro Anual da Associação Nacional dos Cursos de Pós-graduação em Administração (ENANPAD), 30, 2006, Salvador, Anais... Salvador: ANPAD, 2006. 1CD ROM.

RAMOS, A.G. Uma introdução ao histórico da organização racional do trabalho. Brasília: Conselho Federal de Administração, 2009.

RODRIGUES, M.V.C. Qualidade de Vida no Trabalho. 11 ed. Petrópolis: Vozes, 2007.

SENNETT, R. A corrosão do caráter: as conseqüências pessoais do trabalho no novo capitalismo. 6. ed. Tradução de Marcos Santarrita. Rio de Janeiro: Record, 2007.

. A cultura do novo capitalismo. Rio de Janeiro: Record, 2006.

TAYLOR, F.W. Princípios de administração científica. 7. ed. São Paulo: Atlas, 1986.

TOLFO, S.R.; PICCININI, V. Sentidos e significados do trabalho: explorando conceitos, variáveis e estudos empíricos brasileiros. Psicologia e Sociedade, Porto Alegre, v.19, n. spe, p. 38-46, 2007. Disponível em:<http://www.scielo.br/scielo.php?pid=S010271822007000400007\&script=sci_arttext> Acesso em: 02/02/2013.

VASCONCELOS, A. F. Qualidade de Vida no Trabalho: origens, evolução e perspectivas. Caderno de Pesquisas em Administração, São Paulo, v.8, n.1, janeiro/março, 2001.

VERGARA, S.C. Projetos e Relatórios de Pesquisa em Administração. São Paulo: Atlas, 2006. 
VIEIRA, M. M. F.; CALDAS, M. P. Teoria Crítica e Pós-modernismo: Principais alternativas à hegemonia Funcionalista. Revista de Administração de Empresas. São Paulo, v. 46, n. 1, p. 59-70, jan-mar, 2006.

Artigo recebido em: 10/05/2014

Aprovado em: 14/06/2014 